\title{
Does One More Time Verbalization's Sequence Increases the Progression of Motor Learning
}

\author{
Rim Mekni' ${ }^{1}$, Slim Oueslati ${ }^{1}$, Saber Abdellaoui ${ }^{2}$, Anissa Bouassida ${ }^{1}$, Makrem Zghibi $^{1}$ \\ ${ }^{1}$ Research Unit, Sportive Performance and Physical Rehabilitation, High Institute of Sports and Physical Education of Kef, \\ University of Jendouba, Kef, Tunisia \\ ${ }^{2}$ Higher Institute of Sports and Physical Education, Ksar-Said, Tunisia \\ Email: makwiss@yahoo.fr
}

How to cite this paper: Mekni, R., Oueslati, S., Abdellaoui, S., Bouassida, A., \& Zghibi, M. (2022). Does One More Time Verbalization's Sequence Increases the Progression of Motor Learning. Creative Education, 13, 329-346.

https://doi.org/10.4236/ce.2022.131020

Received: December 14, 2021

Accepted: January 25, 2022

Published: January 28, 2022

Copyright $\odot 2022$ by author(s) and Scientific Research Publishing Inc. This work is licensed under the Creative Commons Attribution International License (CC BY 4.0).

http://creativecommons.org/licenses/by/4.0/

\begin{abstract}
This work studies the effect of the verbalization sequences constructed by the pupils during a cycle of eight basketball sessions in Physical Education and Sport (PES) on motor learning for a mixed class of Tunisian high school pupils. On the one hand, we compare the effects of pupil's discursive productions after a first and a second sequence of verbalization. On the other hand, we consider the differences in the action projects between the language interactions of girls, boys and mixed groups. The observation is used as data collection instruments. The didactic interaction is studied by exercising the quantitative approach to identify hidden intentions. The measured parameters are: played balls, shots and scored baskets. The results of the experiments showed that the practice of learning in condition with verbalization brings positive effects in terms of behavioral modification. The addition of a second sequence of verbalization during the same session is more effective for the learning than the practice under condition of a single sequence application. We suggest to Tunisian PES teachers to give more time to verbalization, pupils learn better after identifying the mechanisms that lead to the success of their action projects and have a more pronounced rate of learning.
\end{abstract}

\section{Keywords}

Verbalization, Gender, Basketball, Action Projects, Didactic Interaction

\section{Introduction}

Verbal interactions between the actors of the teaching/learning process aim at multiplying the studies on their pedagogical aspects (Altet, 1994) and didactics 
(Amade-Escot, 1998; Sarrazy, 2001; Ouesslati et al., 2015). In fact, verbalization is a crucial educational strategy in the interventions of PES teachers (Austin \& Lane, 1970). The difference in meaning between "what is said" and "what is covered" has been taken by "pragmatic discourse" which focuses on the elements of language in the context and in the co-text (Wallian \& Chang, 2007b).

This work examines the importance of the introduction of language interaction sequences produced by pupils during the learning sessions in physical education and sport (PES). Through this manuscript we propose a model of socioconstructivist learning based on the concept of "socio-cognitive conflict". This model anchored in constructivism emphasizes social interaction as an effective way to improve knowledge and help build human intelligence. Such work can make an interesting contribution to the sciences of the intervention in pedagogical and didactic terms in the field of PES. Indeed, PES is an integral part of the Tunisian education system. Tunisian pupils take two to three hours of PES per week during their primary and secondary school. These sessions are mixed; they are structured in disciplinary learning cycles. The aim of this study is to take into account the pupils' point of view and how they co-construct their knowledge in and through action (Zghibi et al., 2013a).

Several literature reviews have examined the effects of verbalization by the pupils on his motor learning in contexts and with different aims of verbalization. In dance, (Lafont \& Martin, 2014) demonstrated that the verbal production of a sequence observed by young pupils was effective only if the teacher had previously had recourse to the explicit demonstration, that is to say If he had accompanied his demonstration of verbal information (comments, explanations). In the same context, Weiss, Ebbeck and Rose (1992, cited by Cadopi, 2005) worked on younger pupils aged 5 to 10 years (verbal explanation without demonstration and/or direct reproduction of the sequence without verbal repetition). These authors have suggested that the pupil verbalize in order to elaborate a representative coding and an internal reference allowing him to reproduce the sequence demanded by the teacher, but also to evaluate those that he executes (Cadopi, 2005). Another research conducted by Elandoulsi (2006) has demonstrated positive effects on the motor acquisition of a gymnastic gesture. Similarly, in team sports such as volleyball (Keukelaere, Guérin, \& Saury, 2008), In handball (Darnis \& Lafont, 2008, 2013) showed that the effect of verbalization was more effective in male dyads (Darnis-Paraboschi et al., 2005) and asymmetric dyads in favor of the less competent pupils (Darnis \& Lafont, 2008, 2013).

As a discourse in an educational setting, verbal production or negotiation is the set of observable statements produced between pupils. These negotiations aim to improve the game of pupils in a collective sport learning cycle (basketball) in the educational context of PES. Social inequality between girls and boys can play a key role on the team sport in the learning process based on the verbalization between pairs. In this perspective, this study highlights the effect of language interaction on the behavioral progression change in high school pupils during learning of collective sport. 


\section{Methodology}

The didactic situation proposed in this study consists in allowing a time of discursive interaction in the form of a "debate of ideas" (Grehaigne \& Godbout, 1995; Gréhaigne, 2009) between pupils ( $5 \times 5,3$ teams, boys team, girls team and third mixed team girls and boys aged 17), with/without the teacher, before/after a game $\left(\mathrm{T}=3 \times 8^{\prime}\right)$ in a basketball court (Zghibi, 2009). Each team is composed of 7 players ( 5 participants and 2 substitutes); the mixed team must play with (3 boys and 2 girls).

The data were collected using an observation grid. The observed indicators are: the balls being played (play volume), the shots and scored baskets (offensive capacity) (Gréhaigne et al., 1989). These results will be presented in groups.

Each session is composed of three game situations $\left(\mathrm{T}=8^{\prime}\right)$, under the teacher's control, interspersed with two verbalization sequences $\left(t=3^{\prime}\right)$, one in the presence of the teacher and another in his absence, consisting of narrating the facts and arguing about a collective strategy.

\section{Results}

\subsection{From before to after Sequence 1}

Data collected during the eight game before and after the first sequence of verbalization (boys) are presented in Table 1.

Table 1. Data collected during the eight games before/after the first sequence of verbalization (boys).

\begin{tabular}{ccccc}
\hline & Verbalization & Played ball & Shots to basket & Scored basket \\
\hline Session 1 & Before & 18 & 9 & 2 \\
Session 2 & After & 17 & 8 & 3 \\
& Before & 18 & 9 & 3 \\
Session 3 & After & 18 & 9 & 3 \\
& Before & 17 & 8 & 3 \\
Session 4 & After & 17 & 1 & 5 \\
& Before & 15 & 8 & 5 \\
Session 5 & After & 16 & 8 & 4 \\
& Before & 18 & 1 & 4 \\
Session 6 & After & 17 & 8 & 4 \\
& Before & 16 & 7 & 3 \\
Session 7 & After & 19 & 9 & 5 \\
& Before & 17 & 5 & 3 \\
Session 8 & After & 20 & 9 & 6 \\
& Before & 16 & 10 & 4 \\
\hline \multirow{2}{*}{ After } & 19 & & 7 \\
\hline
\end{tabular}


For boys, the number of played balls increased remarkably at the end of the learning cycle (sixth, seventh and eighth session) with a difference of 03 balls played between the two sets separated by the verbalization sequence (Figure 1).

Regarding the number of shots to the basket showed degradation from before to after verbalization during the first half of the cycle especially for the third session (from 8 to 1 shot) and begins to evolve from the fifth session with a range of progression from 2 to 7 shots (Figure 2).

The number of scored baskets fluctuated from the first to the fifth session. This parameter has improved over the last three sessions of the learning cycle (sixth, seventh and eighth session) with a difference of 2 and 3 scored goals per session after verbalization (Figure 3).

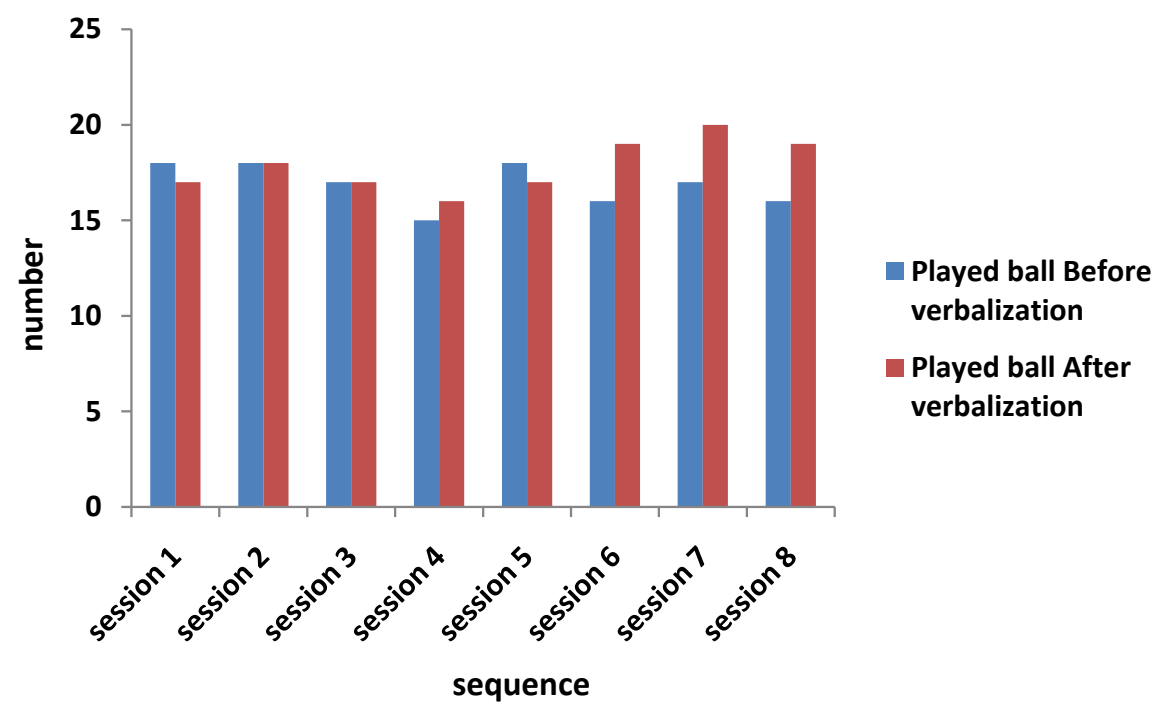

Figure 1. Played ball's number during the eight games before/after the first sequence of verbalization (boys).

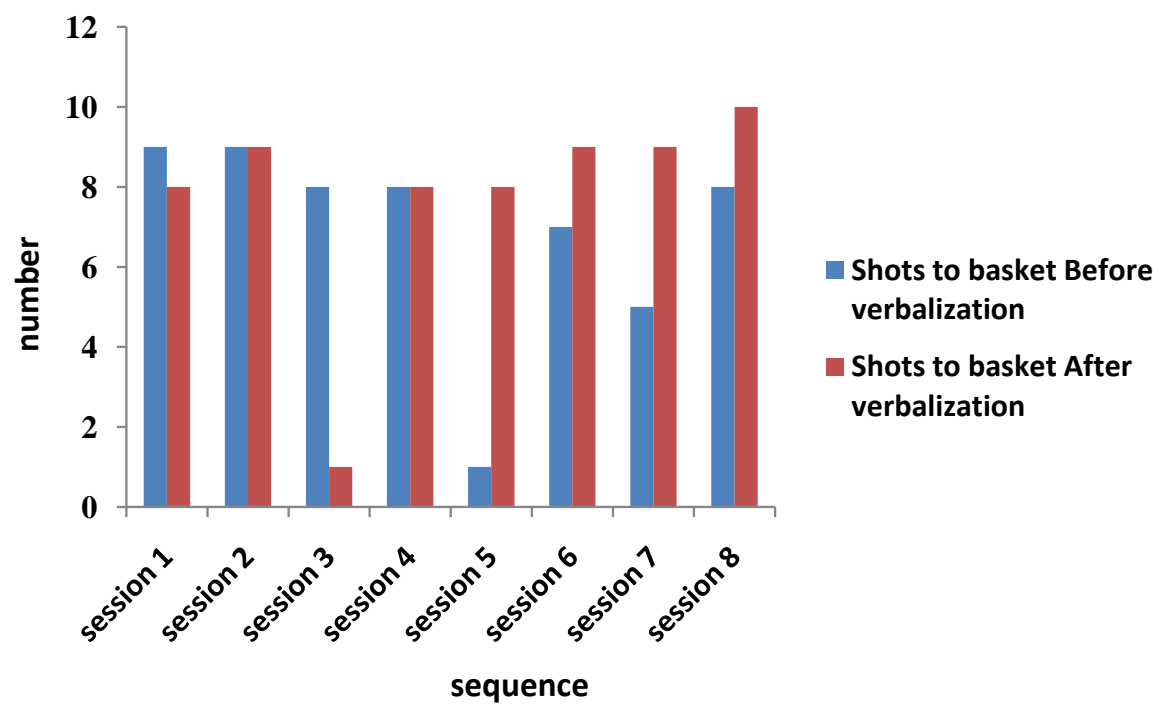

Figure 2. Shots number to basket during the eight games before/after the first sequence of verbalization (boys). 


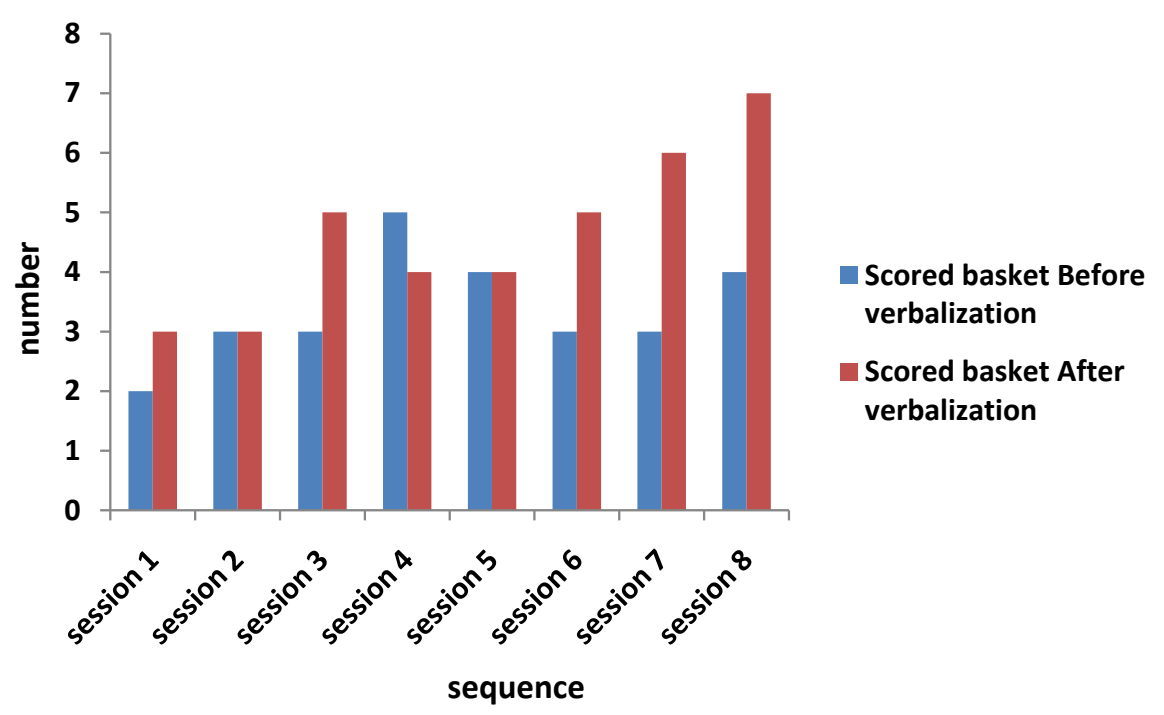

Figure 3. Scored basket's number during the eight games before/after the first sequence of verbalization (boys).

Data collected during the eight games before/after the first sequence of verbalization (girls) are presented in Table 2.

For the girls, the recording of the played balls is devoid of degradation. This parameter remained constant for the sessions ( 3 and 5 ) and improved for the sessions $(1,2,4,6,7$ and 8$)$. The extent of progression ranging from 1 to 4 (Figure 4).

The number of shots showed a fall during a single session (2) where it increased from 8 before the sequence of verbalization to 6 after this sequence. For the rest of the cycle is characterized by a progressive evolution from 1 more shot for the sessions ( 1 and 3), 2 more shots for the sessions (4, 5 and 6), 3 more shots for the session (7) and 4 more shots for the last session (8) (Figure 5).

The number of recorded baskets is improved in a remarkable way along the learning cycle except for the only session (3) it remains constant. This improvement showed an evolution which extends from 1 to 5 from before to after the verbalization sequence (Figure 6).

Data collected during the eight games before/after the first sequence of verbalization (girls/boys) in Table 3.

For boys/girls group, the number of played balls increased remarkably along the learning cycle except for session (2) it remains constant and during session (1) decreased from 19 before verbalization to 17 after verbalization. The extent of progression is fixed at 1 for the session (3) to 5 more balls played for the session (8) (Figure 7).

Regarding the number of shots to the basket showed degradation from before to after verbalization during the first half of the cycle. This parameter has begun to evolve from the fifth session with a range of progression from 1 to 3 shots (Figure 8).

The number of registered scored baskets showed a continuous improvement 
Table 2. Data collected during the eight games before/after the first sequence of verbalization (girls).

\begin{tabular}{|c|c|c|c|c|}
\hline & Verbalization & Played ball & Shots to basket & Scored basket \\
\hline \multirow{2}{*}{ Session 1} & Before & 16 & 7 & 1 \\
\hline & After & 17 & 8 & 2 \\
\hline \multirow[t]{2}{*}{ Session 2} & Before & 15 & 8 & 3 \\
\hline & After & 17 & 6 & 4 \\
\hline \multirow[t]{2}{*}{ Session 3} & Before & 17 & 7 & 4 \\
\hline & After & 17 & 8 & 4 \\
\hline \multirow[t]{2}{*}{ Session 4} & Before & 16 & 6 & 5 \\
\hline & After & 17 & 8 & 7 \\
\hline \multirow[t]{2}{*}{ Session 5} & Before & 18 & 6 & 4 \\
\hline & After & 18 & 8 & 5 \\
\hline \multirow[t]{2}{*}{ Session 6} & Before & 15 & 7 & 5 \\
\hline & After & 18 & 9 & 8 \\
\hline \multirow[t]{2}{*}{ Session 7} & Before & 16 & 5 & 4 \\
\hline & After & 20 & 8 & 7 \\
\hline \multirow[t]{2}{*}{ Session 8} & Before & 16 & 4 & 2 \\
\hline & After & 20 & 9 & 7 \\
\hline
\end{tabular}

Table 3. Data collected during the eight games before/after the first sequence of verbalization (girls/boys).

\begin{tabular}{lcccc}
\hline & Verbalization & Played ball & Shots to basket & Scored basket \\
\hline \multirow{2}{*}{ Session 1 } & Before & 19 & 8 & 3 \\
Session 2 & After & 17 & 6 & 5 \\
& Before & 17 & 7 & 1 \\
Session 3 & After & 17 & 6 & 2 \\
& Before & 17 & 7 & 3 \\
Session 4 & After & 18 & 7 & 4 \\
& Before & 17 & 6 & 4 \\
Session 5 & After & 19 & 5 & 6 \\
& Before & 16 & 6 & 4 \\
Session 6 & After & 18 & 9 & 6 \\
& Before & 17 & 8 & 5 \\
Session 7 & After & 18 & 8 & 6 \\
& Before & 17 & 5 & 6 \\
\hline \multirow{2}{*}{ Session 8 } & After & 20 & 9 & 6 \\
& Before & 16 & 6 & 7 \\
\hline
\end{tabular}




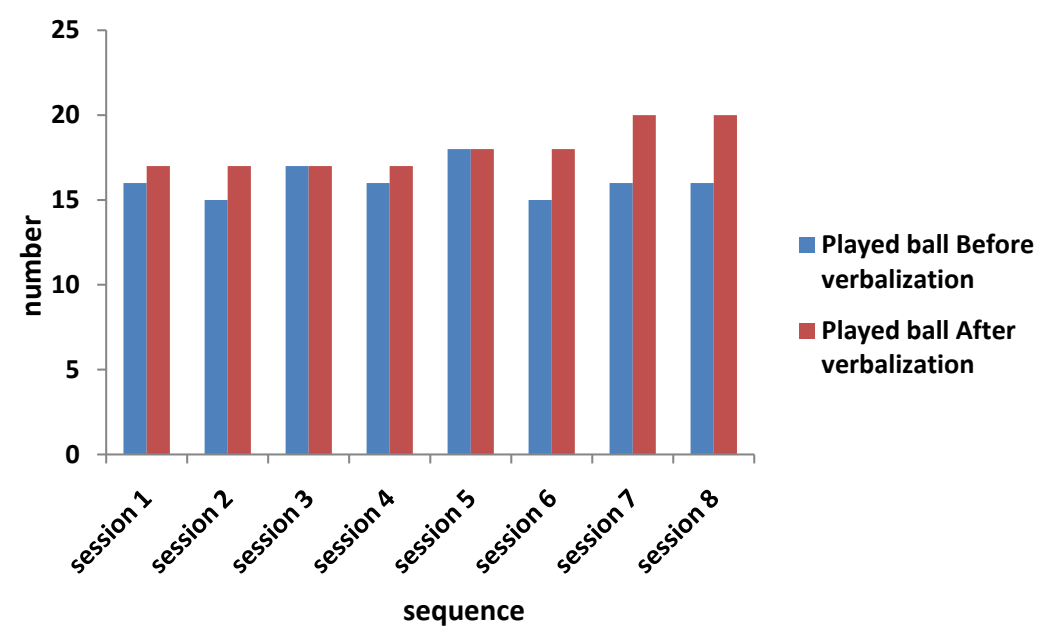

Figure 4. Played ball's number during the eight games before/after the first sequence of verbalization (girls).

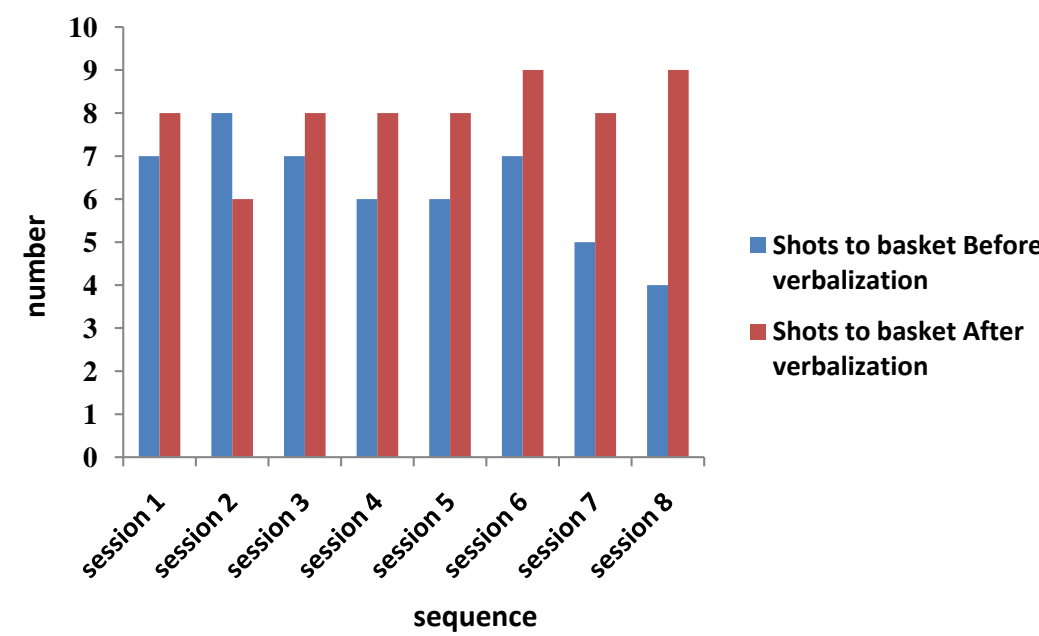

Figure 5. Shots number to basket during the eight games before/after the first sequence of verbalization (girls).

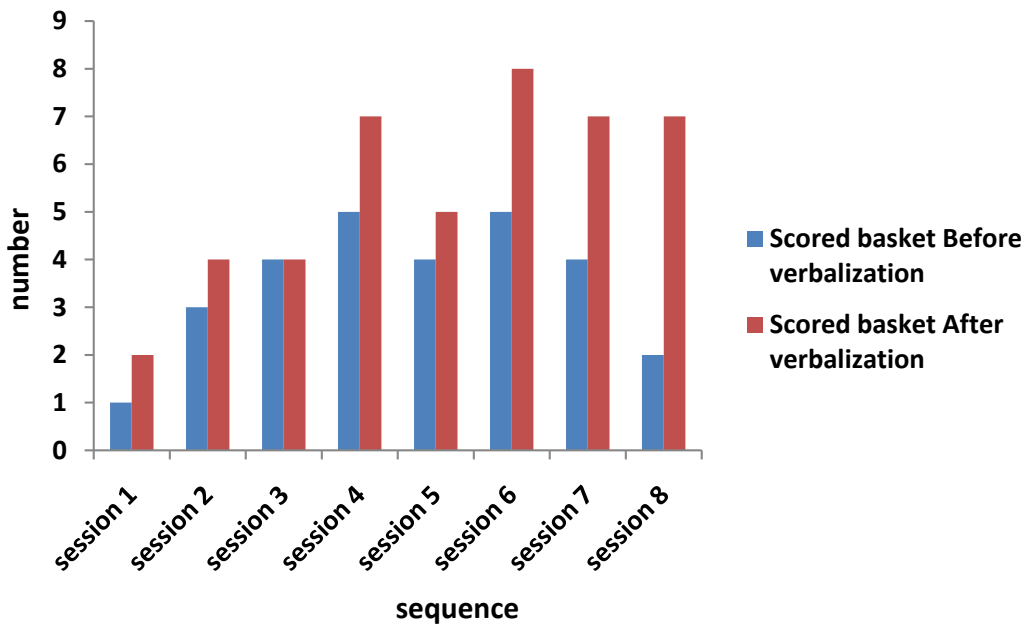

Figure 6. Scored basket's number during the eight games before/after the first sequence of verbalization (girls). 


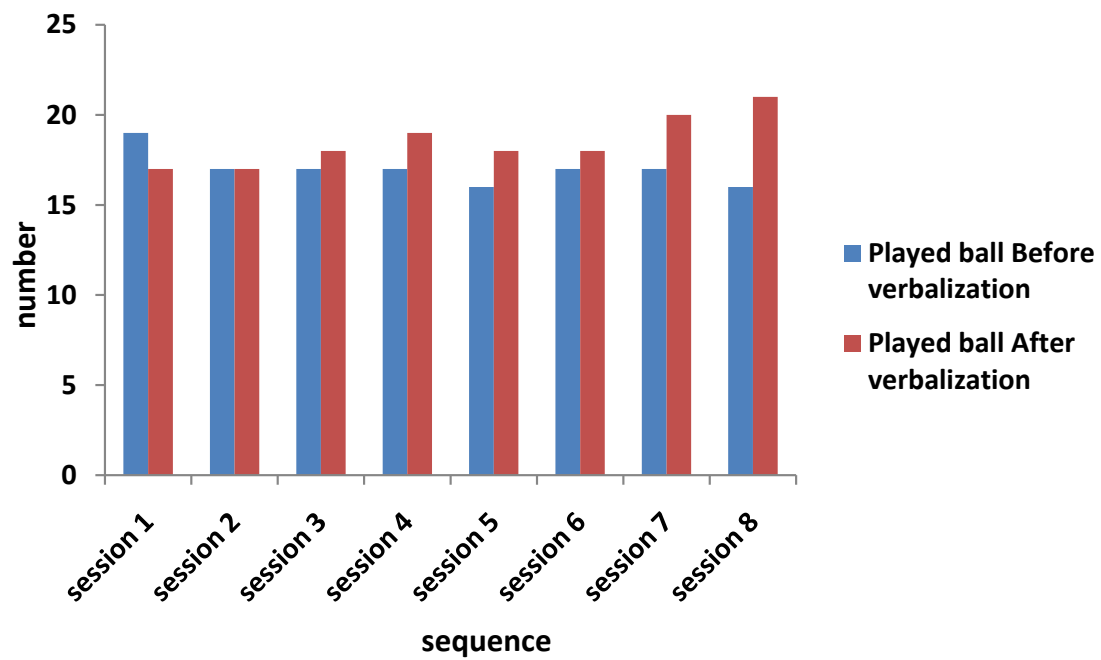

Figure 7. Played ball's number during the eight games before/after the first sequence of verbalization (girls/boys).

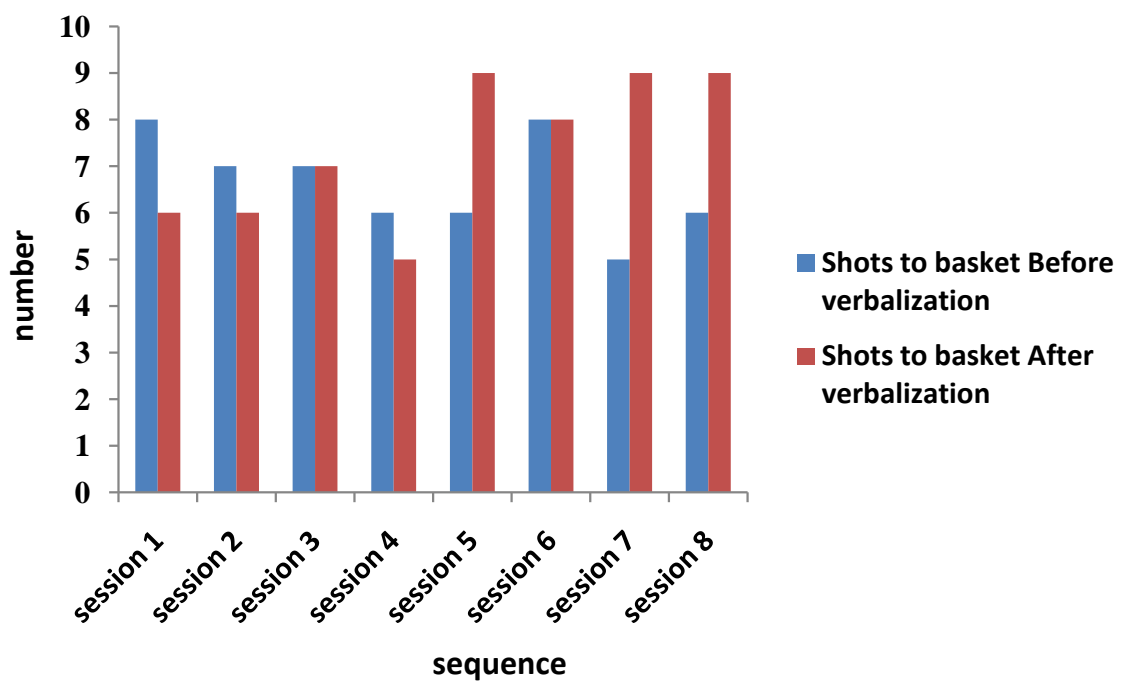

Figure 8. Shots number to basket during the eight games before/after the first sequence of verbalization (girls/boys).

throughout the cycle with an extensive progress that has fluctuated between 1 and 3 scored goals over after verbalization (Figure 9).

\subsection{From before to after Sequence 2}

Data collected during the eight game before and after the second sequence of verbalization (boys) are presented in Table 4.

Improving the level of played balls after the second sequence of verbalization was present from the beginning to the end of the cycle. This offensive parameter showed a considerable margin of progression that ranges from 1 to 6 (Figure 10).

Regarding the number of shots to the basket showed degradation from before to after second sequence of verbalization during the first half of the cycle and 
Table 4. Data collected during the eight games before/after the second sequence of verbalization (boys).

\begin{tabular}{ccccc}
\hline & Verbalization & Played ball & Shots to basket & Scored basket \\
\hline Session 1 & Before & 17 & 9 & 2 \\
Session 2 & After & 19 & 8 & 3 \\
& Before & 18 & 7 & 3 \\
Session 3 & After & 21 & 8 & 3 \\
& Before & 19 & 9 & 4 \\
Session 4 & After & 20 & 6 & 5 \\
& Before & 17 & 8 & 5 \\
Session 5 & After & 20 & 7 & 4 \\
& Before & 20 & 1 & 4 \\
Session 6 & After & 25 & 8 & 5 \\
& Before & 21 & 7 & 3 \\
& After & 26 & 10 & 5 \\
Session 7 & Before & 20 & 7 & 6 \\
& After & 25 & 9 & 9 \\
& Before & 22 & 12 & 5 \\
\hline \multirow{2}{*}{ Session 8 } & After & 28 & & 5 \\
& & & 9 & 5 \\
\hline
\end{tabular}

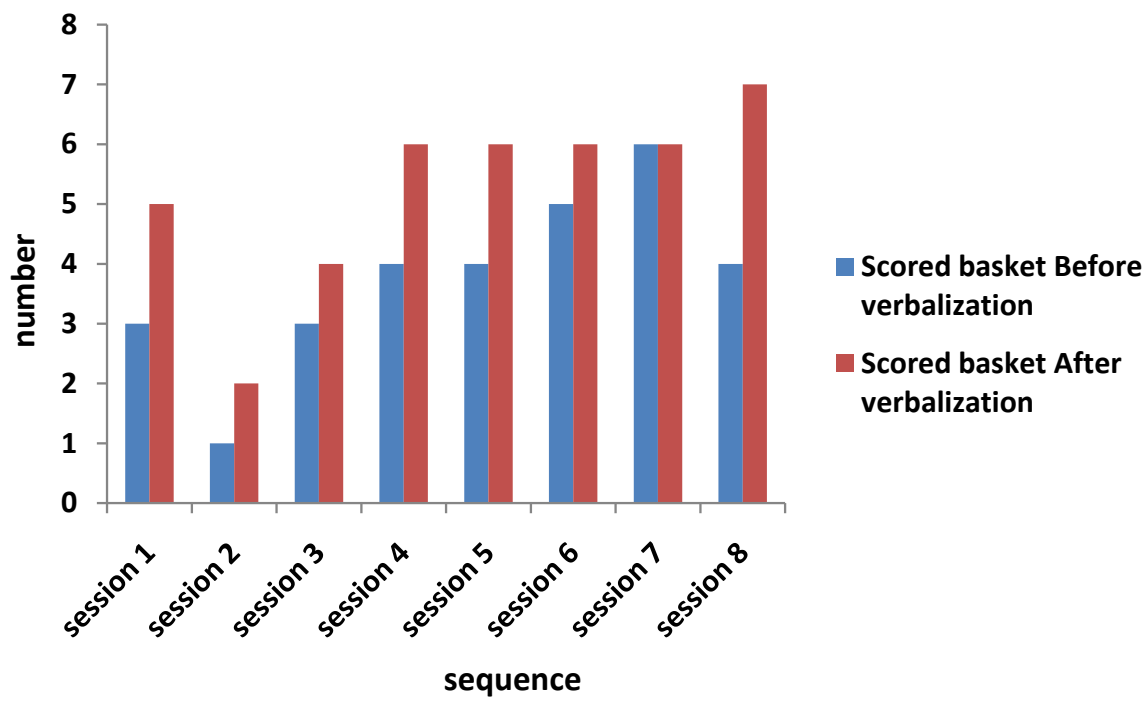

Figure 9. Scored basket's number during the eight games before/after the first sequence of verbalization (girls/boys).

begins to evolve from the fifth session with a range of progression from 1 to 8 shots (Figure 11).

The number of scored baskets has improved over the learning cycle with a difference of 1 and 5 scored goals per session after second verbalization (Figure 12). 


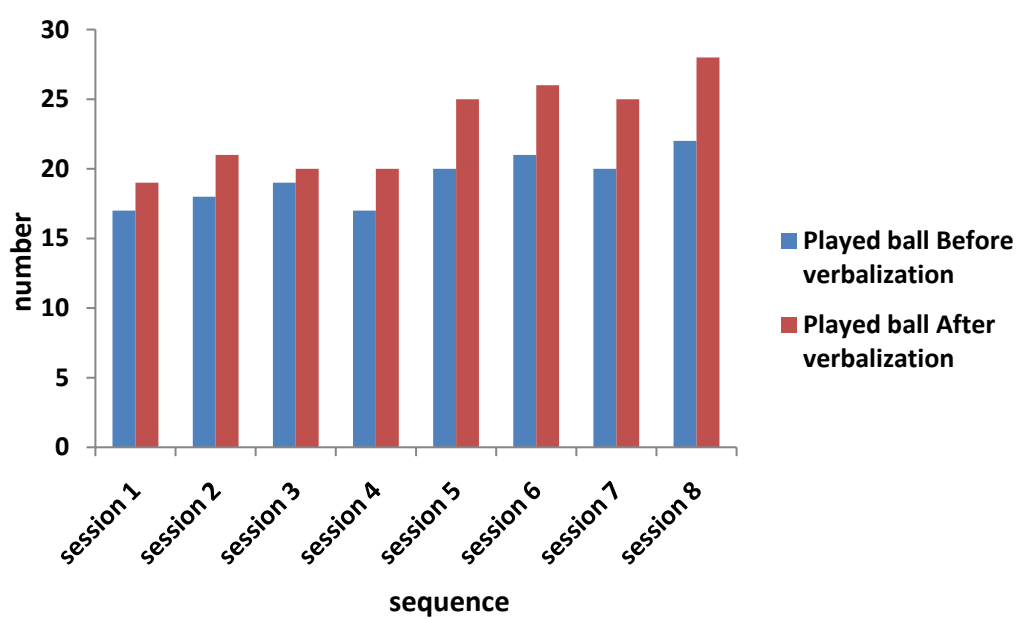

Figure 10. Played ball's number during the eight games before/after the second sequence of verbalization (boys).

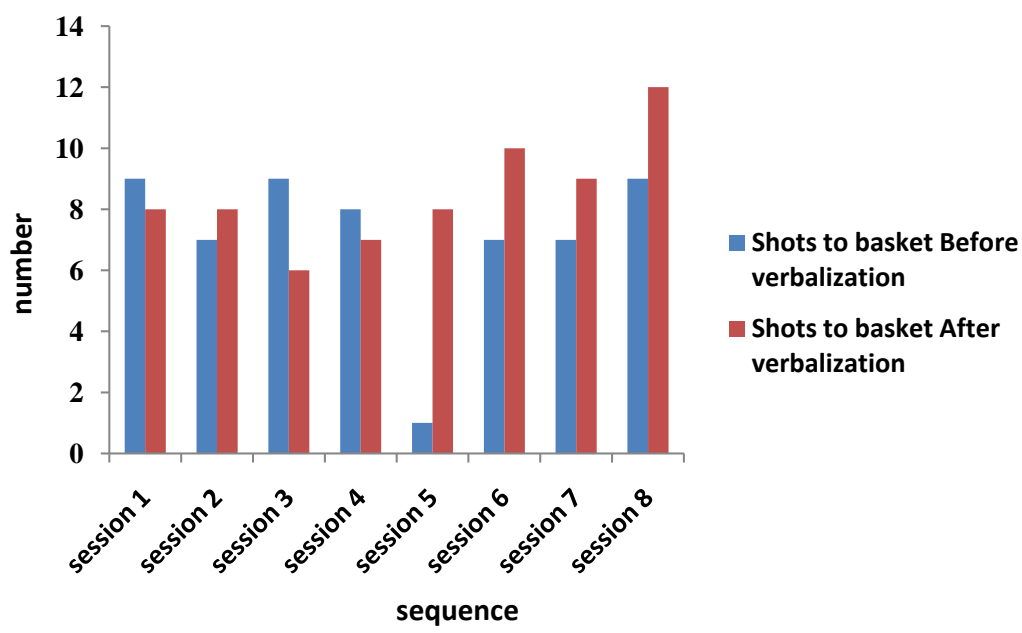

Figure 11. Shots number to basket during the eight games before/after the second sequence of verbalization (boys).

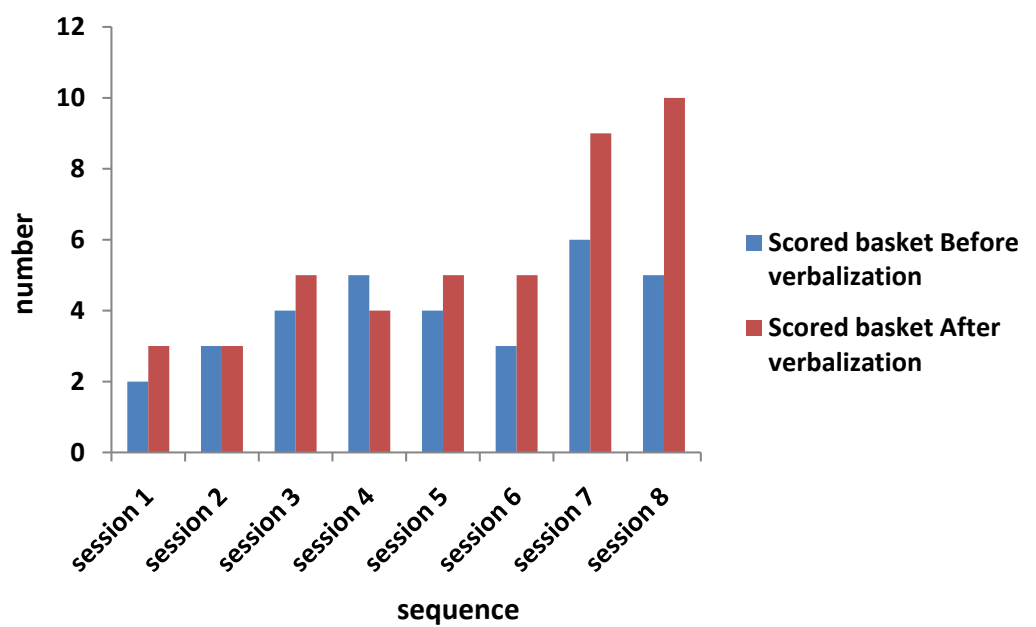

Figure 12. Scored basket's number during the eight games before/after the second sequence of verbalization (boys). 
Data collected during the eight games before/after the second sequence of verbalization (girls) are presented in Table 5.

For girls, the number of played balls increased remarkably over the learning cycle. This parameter evolved during the first half of the cycle with a minimal range of progression which ranged from 1 to 2 . For the second half, it was established with a range that fluctuated from 5 to 7 (Figure 13).

Table 5. Data collected during the eight games before/after the second sequence of verbalization (girls).

\begin{tabular}{lcccc}
\hline & Verbalization & Played ball & Shots to basket & Scored basket \\
\hline Session 1 & Before & 17 & 6 & 1 \\
Session 2 & After & 18 & 8 & 2 \\
& Before & 16 & 7 & 3 \\
Session 3 & After & 18 & 6 & 4 \\
& Before & 16 & 7 & 4 \\
Session 4 & After & 17 & 7 & 4 \\
& Before & 17 & 9 & 5 \\
Session 5 & After & 18 & 8 & 7 \\
& Before & 17 & 6 & 4 \\
Session 6 & After & 24 & 8 & 5 \\
& Before & 20 & 7 & 6 \\
Session 7 & After & 25 & 9 & 8 \\
& Before & 21 & 5 & 3 \\
Session 8 & After & 26 & 8 & 7 \\
& Before & 20 & 4 & 3 \\
& After & 26 & 7 & 8 \\
\hline
\end{tabular}

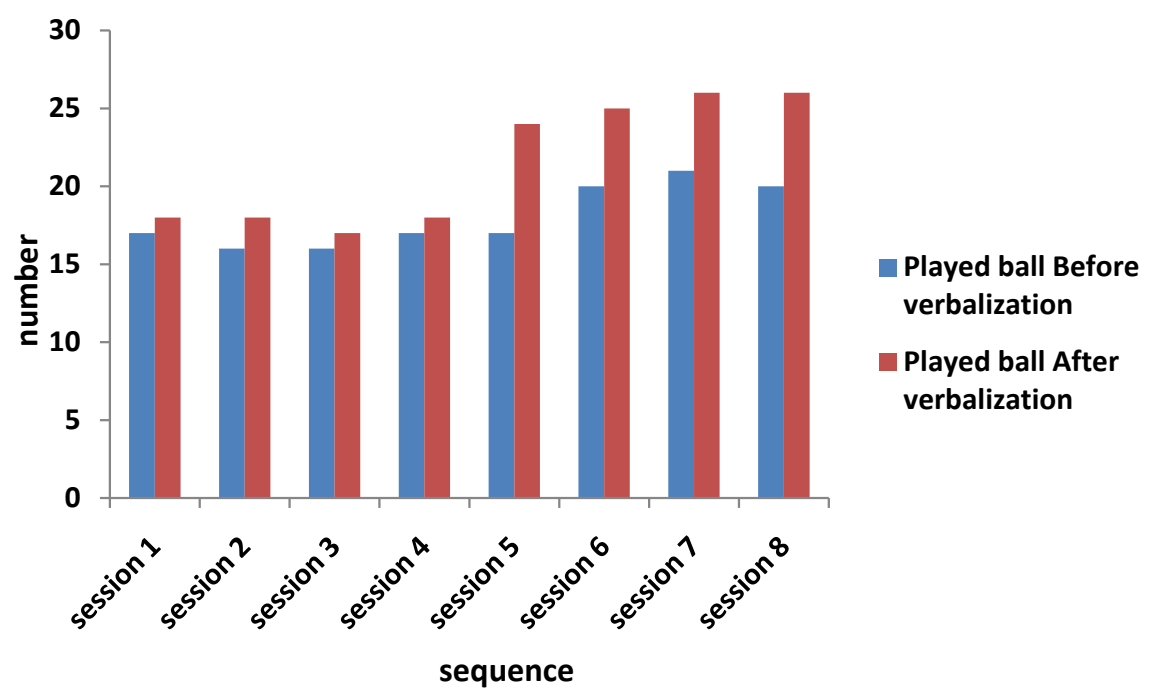

Figure 13. Played ball's number during the eight games before/after the second sequence of verbalization (girls). 
Concerning the number of shots to the basket showed degradation from before to after second sequence of verbalization during the first half of the cycle and begins to evolve from the fifth session with a range of progression from 2 to 3 shots (Figure 14).

The number of scored baskets has improved over the learning cycle with a difference of 1 and 5 scored goals per session after second verbalization (Figure 15).

Data collected during the eight games before and after the second sequence of verbalization (girls/boys) are presented in Table 6.

For boys/girls group, the number of played balls increased remarkably from session (3) to the end of cycle from 1 to 6 after second sequence of verbalization (Figure 16).

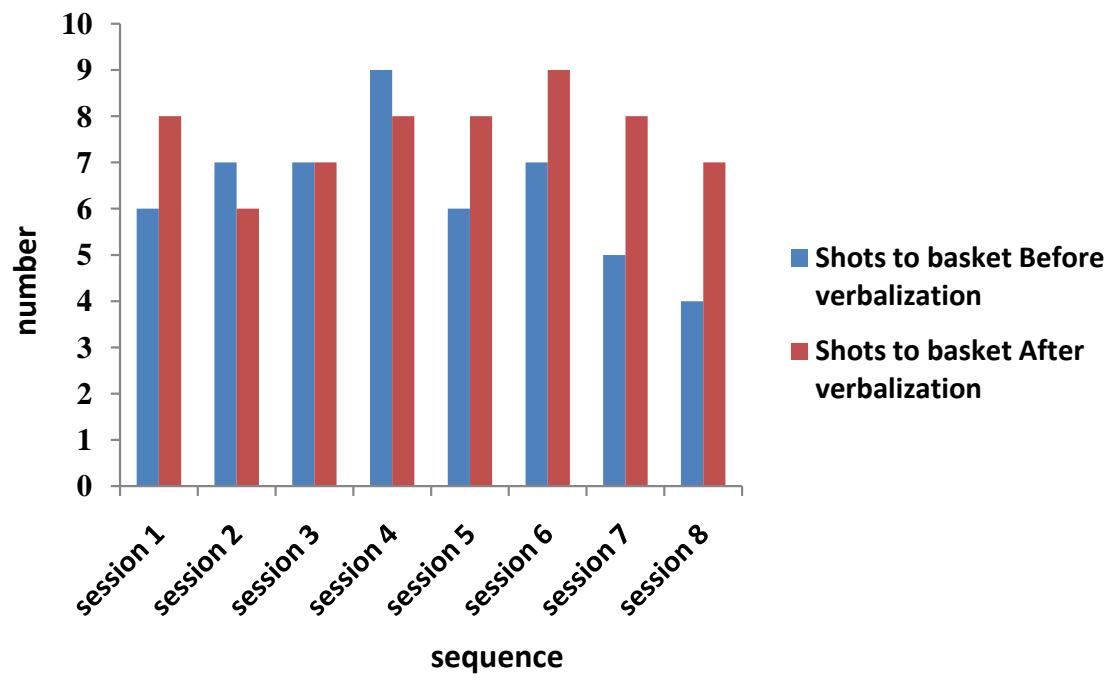

Figure 14. Shots number to basket during the eight games before/after the second sequence of verbalization (girls).

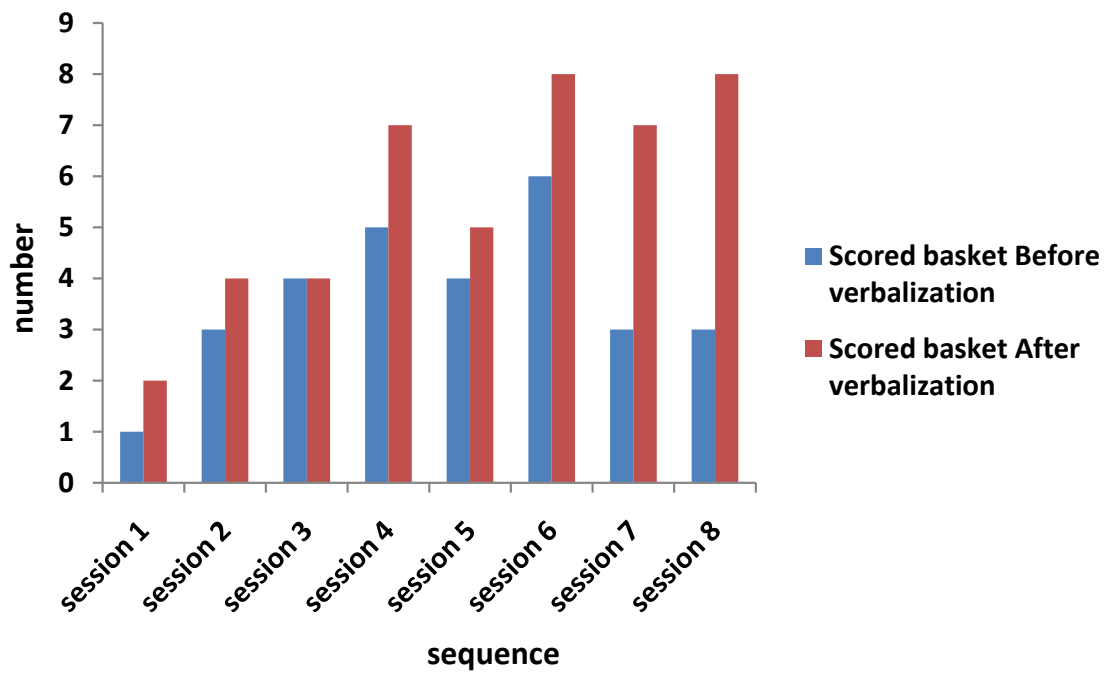

Figure 15. Scored basket's number during the eight games before/after the second sequence of verbalization (girls). 
Table 6. Data collected during the eight games before/after the second sequence of verbalization (girls/boys).

\begin{tabular}{ccccc}
\hline & Verbalization & Played ball & Shots to basket & Scored basket \\
\hline Session 1 & Before & 18 & 9 & 3 \\
Session 2 & After & 16 & 7 & 5 \\
& Before & 18 & 7 & 1 \\
Session 3 & After & 18 & 8 & 2 \\
& Before & 17 & 8 & 3 \\
Session 4 & After & 18 & 8 & 4 \\
& Before & 17 & 7 & 4 \\
Session 5 & After & 19 & 8 & 6 \\
& Before & 17 & 6 & 4 \\
Session 6 & After & 20 & 9 & 6 \\
& Before & 19 & 8 & 5 \\
Session 7 & After & 24 & 10 & 6 \\
& Before & 21 & 6 & 4 \\
Session 8 & After & 27 & 9 & 7 \\
& Before & 20 & 10 & 5 \\
\hline \multirow{2}{*}{ After } & 26 & & 9 \\
\hline
\end{tabular}

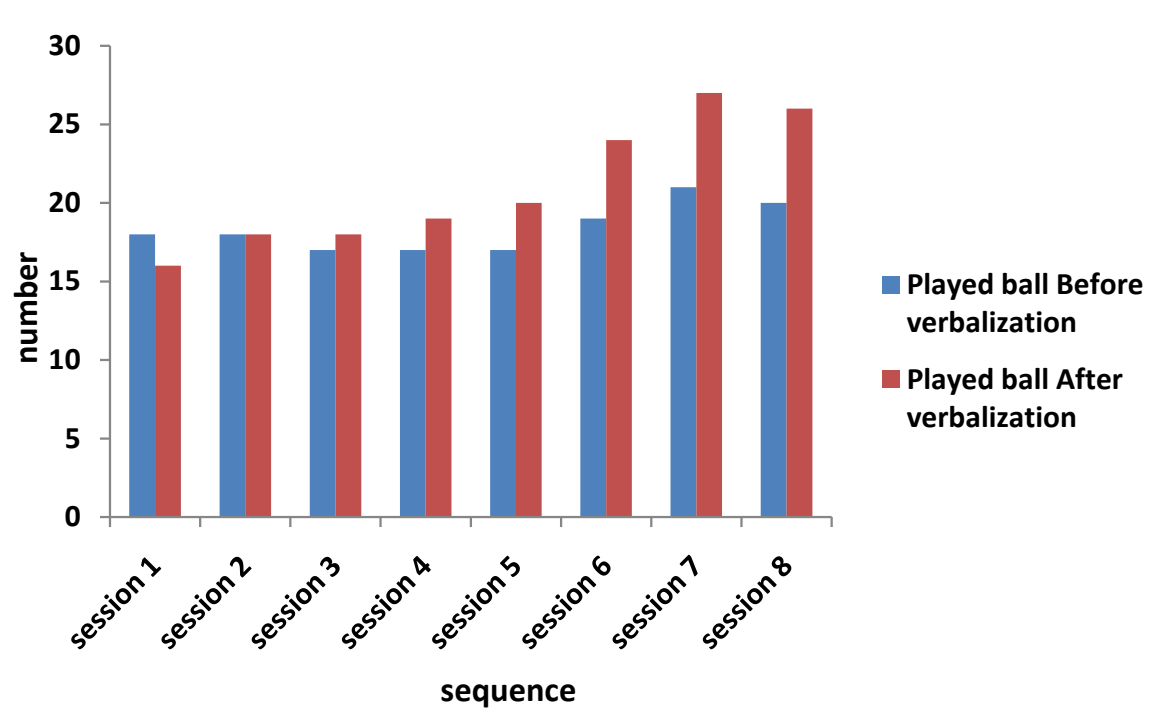

Figure 16. Played ball's number during the eight games before/after the second sequence of verbalization (girls/boys).

The number of shots to the basket has improved over the learning cycle (from second session) with a difference of 1 and 3 scored goals per session after second verbalization (Figure 17).

The number of scored baskets has improved over the learning cycle with a difference of 1 and 4 scored goals per session after second verbalization (Figure 18). 


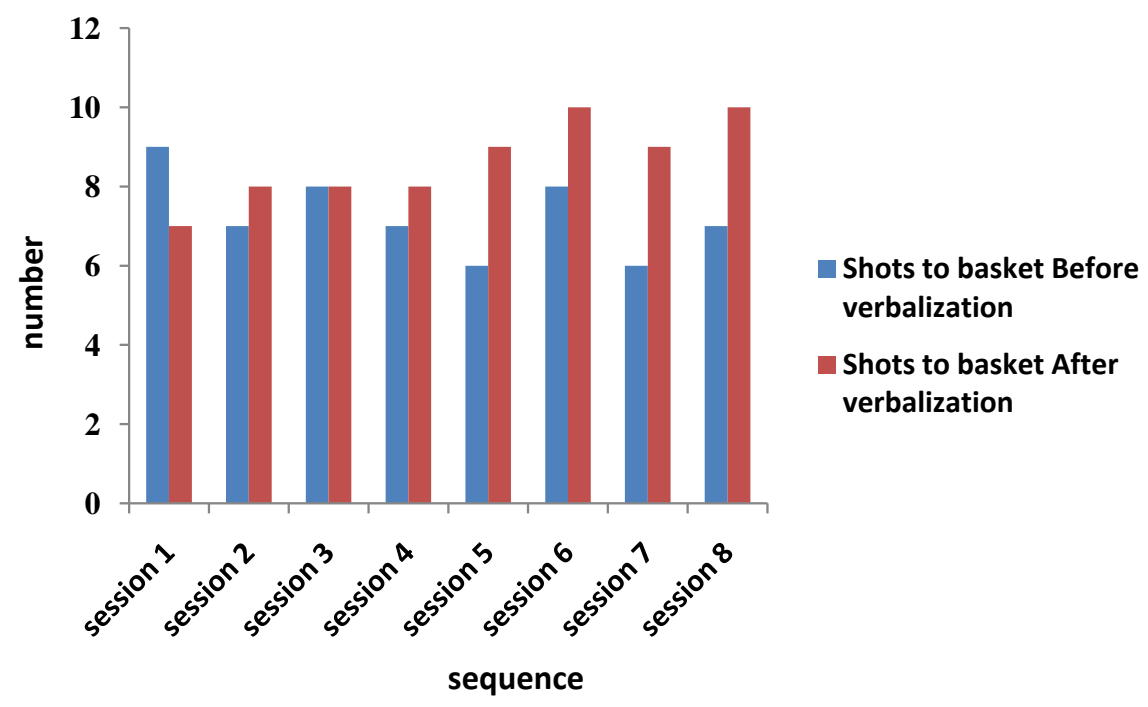

Figure 17. Shots number to basket during the eight games before/after the second sequence of verbalization (girls/boys).

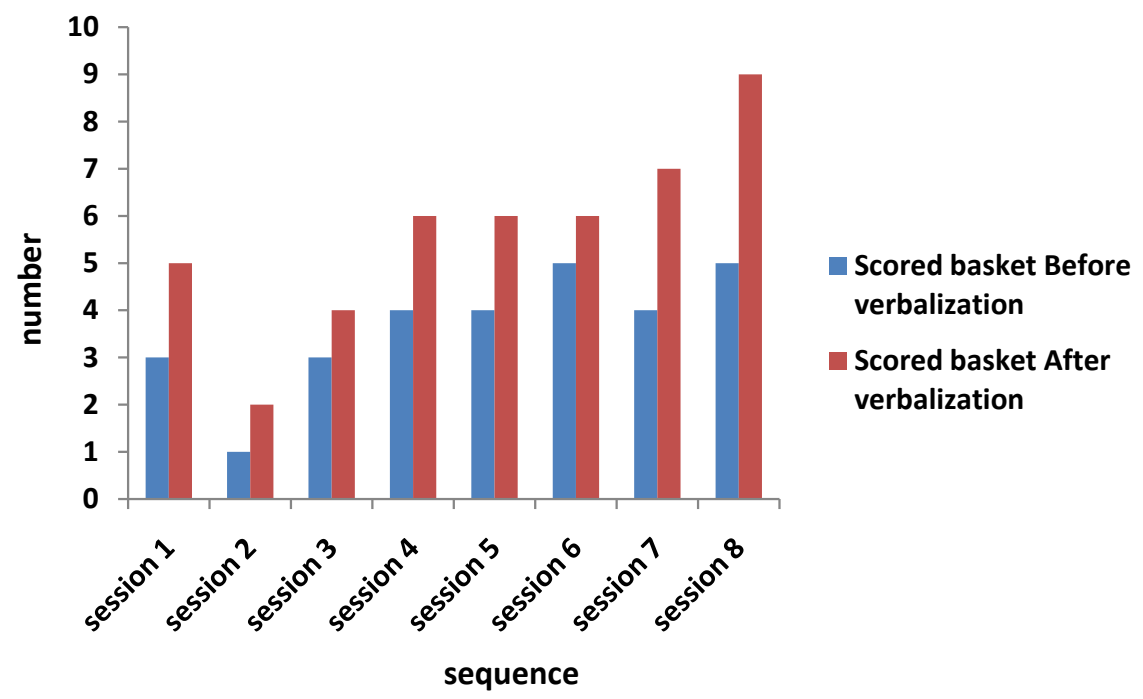

Figure 18. Scored basket's number during the eight games before/after the second sequence of verbalization (girls/boys).

\section{Discussion}

Teacher is always in perpetual search for facilitating the action of teaching, the transmission and acquisition of knowledge. In this context, it makes use of the strategy of verbalization which still remains untapped in the Tunisian education sector in terms of PES.

In this perspective, this study highlights the effect of language interaction on the behavioral progression change in high school pupils during learning cycle of collective sport such as basketball.

The results of the experiments showed that the practice of learning in condition with verbalization brings positive effects in terms of behavioral modification. The addition of a second sequence of verbalization during the same session 
is more effective for the learning than the practice under condition of a single sequence application.

Our findings are consistent with (Zerai et al., 2008, Chang, 2009, Zghibi, 2009) who have reported that the introduction of collective sport verbalization has a beneficial effect on student investment in motor Learning. It seems that the role of the information added by the verbalization during a second sequence of verbalization led students to better interact and produce qualitative indications on the characteristics of the action. The importance of transition information (strategic information about what needs to be done in the next game) provides the best knowledge in terms of future student activities and the promotion of motor learning.

Motor learning is organized and controlled by essentially cognitive processes (Alibali et al., 2000; Bastien, 1987) with divergence in the degree of awareness (Chikoko, 2007; Biao, 2013).

Fleurance (1991) affirmed that there is a part of knowledge, of the necessary awareness of motor learning which evolves rapidly in favor of an infra-conscious cognitive process. In the same context, (Bouthier, 1988; Grehaigne et al., 1989) suggested that the approach based on the awareness of action rules through verbalization seems the most relevant to meet the aims of the PES.

The results suggested that requiring students to communicate with each other after each game makes it possible to modify their responses in an evolutionary way with progression ranges from minimal (after the first sequence) to important (after the second sequence). The degree of evolution was more marked in the boys than in the girls especially for the parameters played balls (volume of the game) and scored baskets.

The offensive parameters measured in this study showed fluctuations (ups and downs) after the first sequence of verbalization. Boys seem to be more sensitive to verbalization sequences than girls (Zghibi et al., 2013a, 2013b, 2014) both after the first and second sequences. Zghibi et al. (2014) declared that girls appear to be involved in the discussion, their statements are less numerous, and their analytic statements less effective than those of boys.

An additional sequence of verbalization presents a strategy to support the development of knowledge in collective sport (Wallian \& Chang, 2007a, 2007b) in order to improve the action projects of players and teams both for boys and girls. This strategy contributes to the development of reinvestable resources (attitudes, motor skills) (Nachon, 2004) and allows students to compare their information and knowledge in order to complete and reconsider their representations in order to improve the effectiveness of their actions.

Verbalisation is a phenomenon of constructivist negotiation (Bronckart, 1997; 2009) in the learning of collective sports. Discussion is central to learning (Cottinet and Harmand, 2003), which provides feedback on whether or not to admit the team's action plan by returning to the strategy (Grehaigne, 1996).

The key role of verbalization and explanation, regardless of learning stage or gender (Grehaigne and Godbout, 1995), allows learning situations to evolve in 
the direction of increasing efficiency, Commitment and active search for solutions on the part of pupils. It is legitimate to note certain limits to this study. We have not given interpretation to the qualitative analysis of linguistic productions of girls and boys, a survey on this issue is necessary to focus on the relationship between words and action. Crossing the qualitative and quantitative analysis allows us to have more detailed findings.

\section{Conclusion}

In a framework of socio-constructivist approach to motor learning (Wallian \& Chang, 2007a), the allocation of more time to verbalization (Grehaigne, 2009) regardless of stage or condition of learning (group girls, Boys or mixed), pupils learn better after identifying the mechanisms that lead to the success of their action projects and have a more pronounced rate of learning. The study also supports the work of (Zghibi et al., 2014) who suggested a redefinition of the divisions of social roles according to gender in the Tunisian educational context of collective sports in terms of PES.

\section{Conflicts of Interest}

The authors declare no conflicts of interest regarding the publication of this paper.

\section{References}

Alibali, M. W., Kita, S., \& Young, A. J. (2000). Gesture and the Process of Speech Production: We Think, Therefore We Gesture. Language and Cognitive Processes, 15, 593-613. https://doi.org/10.1080/016909600750040571

Altet, M. (1994). The Professional Development of Teachers: Analysis of Practices and Teaching Situations. University Press of France.

Amade-Escot, C. (1998). The Teacher of Physical Education and Sport in the Didactic Interactions: Research Itinerary. Doctoral Dissertation.

Austin, J. L., \& Lane, G. (1970). When to Say, Is to Do.

Bastien, C. (1987). Schemes and Strategies in the Cognitive Activity of the Child. University Press of France.

Biao, I. (2013). The Place of Transformative Learning in the Building of Learning Cities in Africa. Journal of Adult and Continuing Education, 19, 3-16. https://doi.org/10.7227/JACE.19.1.2

Bouthier, D. (1988). Contribution of Psychology to the Problematic of Training of Collective Sports Actions. Doctoral Dissertation, PhD Thesis, EPHE, University Paris V. Paris, France.

Bronckart, J. P. (1997). Language Activity, Texts and Discourses. For Socio-Discursive Interactionism.

Bronckart, J. P. (2009). Learning and Development in the Perspective of Socio-Discursive Interactionism. eJRIEPS-e Journal de la Recherche sur IIntervention en Éducation Physique et Sport, 18, 5-23.

Cadopi, M. (2005). The Dancers Motor Skills: A Cognitive Approach. Psychology Bulletin, 475, 29-37. https://doi.org/10.3917/bupsy.475.0029 
Chang, C. W. (2009). Language, Thinking and Action: Semio-Constructivist Approach to the Learning of Play in Basketball for the Pupil of CM2 (5th Grade). Doctoral Dissertation.

Chikoko, V. (2007). The School Cluster System as an Innovation: Perceptions of Zimbabwean Teachers and School Heads. Africa Education Review, 4, 42-57. https://doi.org/10.1080/18146620701412142

Cottinet, C., \& Harmand, M. (2003). Verbalize to Learn, a Central Activity in EPS.

Darnis, F., \& Lafont, L. (2008). Effects of the Dissymmetry of Competence for a CoOperative Learning in Dyads in Physical and Sports Education. International Social Psychology Books, 79, 69-83. https://doi.org/10.3917/cips.079.0069

Darnis, F., \& Lafont, L. (2013). Cooperative Learning and Dyad Interactions: Two Modes of Knowledge Construction in Socio-Constructivist Settings for Team-Sport Teaching. Physical Education and Sport Pedagogy, 20, 1-15.

https://doi.org/10.1080/17408989.2013.803528

Darnis-Paraboschi, F., Lafont, L., \& Menaut, A. (2005). A Social-Constructivist Approach in Physical Education: Influence of Dyadic Interactions on Tactical Choices in an Instructional Team Sport Setting. European Journal of Psychology of Education, 20, 171184. https://doi.org/10.1007/BF03173506

Elandoulsi, S. (2006). Effects of Verbal Intercommunications between Pupils on Motor Learning: Example of Learning of the Handstand in Gymnastics. Staps, 74, 41-45.

https://doi.org/10.3917/sta.074.0041

Fleurance, P. (1991). Place and Roles of Representations in Motor Learning. In J. P. Famose, P. Fleurance, \& Y. Touchard (Eds.), Motor Learning. Role of Representations, (pp. 81-95). revue EPS.

Grehaigne, J. F. (1996). The Rules of Action: A Support for Learning. EPS Review, 265, 71-73.

Gréhaigne, J. F. (2009). Around the Time: Learning, Spaces, Projects in Collective Sports. Presses Univ. Franche-Comte.

Grehaigne, J. F., \& Godbout, P. (1995). Tactical Knowledge in Team Sports from a Constructivist and Cognitivist Perspective. Quest, 47, 490-505.

https://doi.org/10.1080/00336297.1995.10484171

Grehaigne, J. F., Billard, M., Guillon, R., \& Roche, J. (1989). Towards a Different Conception of the Teaching of Collective Sports. In Methodology and Didactics of Physical and Sports Education (pp. 155-172).

Keukelaere, C. D., Guérin, J., \& Saury, J. (2008). Co-Construction of Knowledge in Physical Education during a Training Situation in Volley Ball. Staps: International Journal of Sport Science and Physical Education, 29, 23-38. https://doi.org/10.3917/sta.079.0023

Lafont, L., \& Martin, L. (2014). Learning and Teaching in Physical Activities with an Artistic Dimension: Theoretical Considerations and Research Results. Staps, 103, 39-52. https://doi.org/10.3917/sta.103.0039

Nachon, M. (2004). Interactions in Physical Education and Sport: The Case of Basketball: An Approach to Semio-Language Skills and the Construction of Knowledge. Doctoral dissertation, University of Franche-Comté, UFR of Language, Human and Society Sciences.

Ouesslati, N., Mekni, R., Sahli, H., \& Bouassida, A. (2015). Verbalization in Sport and Physical Education Study of Volleyball Teachers Conceptions. Creative Education, 6, 1603. https://doi.org/10.4236/ce.2015.614161

Sarrazy, B. (2001). Teacher-Student Interactions in Mathematics Education. Contribution 
to an Anthropo-Didactic Approach to Teaching Phenomena. French Review of Education, 136, 117-132. https://doi.org/10.3406/rfp.2001.2832

Wallian, N., \& Chang, C. W. (2007a). Language, Thinking and Action: Towards a Semio-Constructivist Approach in Physical Education. Physical Education and Sport Pedagogy, 12, 289-311. https://doi.org/10.1080/17408980701610219

Wallian, N., \& Chang, C. W. (2007b). Semiotics of Motor Action and Language Activities: Towards an Epistemology of Knowledge Co-Constructed in Collective Sports. In J. F. Gréhaigne (Ed.), Configurations of the Game. Debate of Ideas and Learning of Football and Team Sports (pp. 145-164).

Zerai, Z., Rezig, M., \& Zhigbi, M. (2008). Debates of Ideas and Learning among Girls in Collective Sport. e Journal of Research on Intervention in Physical and Sports Education, 13, 78-93.

Zghibi, M. (2009). Language Interactions of Students and Learning in Football: The Case of Four Classes of 9th Year Basic in Tunisia. Doctoral Dissertation.

Zghibi, M., Guinoubi, C., Bennour, N., \& Moheiddine, N. (2013a). Debate of Ideas and Implementation of the Projects of Actions in Football Game: Cases of the Boys of Third Year Secondary in Tunisia. Sport Science Review, 22, 151-180.

https://doi.org/10.2478/ssr-2013-0008

Zghibi, M., Sahli, H., Bennour, N., Guinoubi, C., Guerchi, M., \& Hamdi, M. (2013b). The Pupils Discourse and Action Projects: The Case of Third Year High School Pupils in Tunisia. Creative Education, 4, 165. https://doi.org/10.4236/ce.2013.43024

Zghibi, M., Sahli, H., Jabri, M., Ouelhezi, S., Guelmemi, N., \& Wallian, N. (2014). Modalities of Decision Making for Girls and Boys in the Presence or Absence of the Teacher. International Review of Education, 59, 751-769.

https://doi.org/10.1007/s11159-013-9397-6 